\title{
ASSOCIATION OF SERUM HOMOCYSTEINE AND SERUM LIPID WITH ECLAMPSIA
}

\author{
Mahal $\mathrm{M}^{1}$, Yeasmin $\mathrm{F}^{2}$, Amin SAKMN ${ }^{3}$, Shahnaj $\mathrm{A}^{4}$, Rashid $\mathrm{M}^{5}$, Hossain $\mathrm{MS}^{6}$
}

\begin{abstract}
Eclampsia is one of the most common pregnancy complications causing high mortality and morbidity for both mother and foetus especially in developing countries. Many studies suggest that elevated homocysteine level is an important risk factor for eclampsia. The aim of this study was to explore the association between serum homocysteine with eclampsia and to establish serum homocysteine measurement as a reliable test for early detection of eclampsia. In a case control study serum homocysteine and lipid profile were measured in 52 controls (healthy uncomplicated pregnant women) and 50 eclamptic pregnant women. Serum homocysteine in eclampsia cases $(10.44 \pm 4.08 \mu \mathrm{mol} / \mathrm{L})$ found to be significantly increased $(p<0.001)$ compared to controls $(7.97 \pm 3.46$ $\mu \mathrm{mol} / \mathrm{L})$. Serum HDL-cholesterol concentration found to be significantly decreased $(p<0.001)$ in the cases $(35.98 \pm 6.35 \mathrm{mg} / \mathrm{dl})$ compared to controls $(42.69 \pm 6.09$ $\mathrm{mg} / \mathrm{dl}$ ). A significant negative correlation ( $\mathrm{r}-.801$, $\mathbf{p}<0.01$ ) was found between serum homocysteine and HDL-cholesterol concentration among cases. It can be concluded that elevated serum homocysteine and HDL-cholesterol deficiency were associated with eclampsia. But elevated homocysteine itself might be a factor associated with eclampsia irrespective of lipid profile status.
\end{abstract}

Key Words: Homocysteine, Eclampsia.

\section{Introduction}

Pre-eclampsia/eclampsia is a pregnancy specific disorder, which complicates $7-10 \%$ of all gestations ${ }^{1}$. Approximately $10-15 \%$ of maternal deaths in developing countries are associated with pre-eclampsia and eclampsia $^{2}$. Pre-eclampsia is a triad of oedema, hypertension and proteinuria occurring primarily after the 20th gestational week and most frequently near term ${ }^{3}$. Pre-eclampsia when complicated with convulsion and or coma is called eclampsia ${ }^{4}$. Intrauterine growth retardation (IUGR), pre-term delivery, low birth weight, foetal death and neonatal death due to complications of pre-term delivery are common perinatal outcomes associated with pre-eclampsia 5 .

Pre-eclampsia and eclampsia is still regarded as "a disease of theories" and its etiology is still obscured.
Endothelial cell dysfunction appears to be a central feature in the pathophysiology of pre-eclampsia ${ }^{6}$. Homocysteine is a sulfur containing amino acid primarily derived from the metabolic demethylation of dietary methionine required for the growth of cells and tissue in the human body ${ }^{7}$. Most recently homocysteine has been claimed as a factor for vascular endothelial cell injury in pre-eclampsia and its consequences ${ }^{8}$. Homocysteine by auto oxidation generates super oxide and hydrogen peroxide, both of which damage the arterial endothelial lining or cause endothelial dysfunction'.

Levels of maternal serum homocysteine normally decreased in normal pregnancy, either due to hemodilution from increased plasma volume or the relative deficiency during pregnancy ${ }^{10}$. Dyslipidemia also plays a role in the aetiopathogenesis of eclampsia ${ }^{5}$. Human gestation is associated with an atherogenic lipid profile that is further enhanced in pre-eclampsia. Such profile may also be a potential contributor to endothelial cell dysfunction, which is a central feature in the pathophysiology of eclampsia ${ }^{11}$. Some studies have demonstrated the relationship between particular serum lipid and levels of homocysteine in eclampsia patients ${ }^{12}$. Eclampsia is associated with 10 percent of maternal deaths and each year approximately 50,000 women worldwide lose their lives out of this complication ${ }^{2}$. Bangladesh is a densely populated country, like many other developing countries, is facing various health related problems including high maternal mortality, which is 3.15 per 1000 women $^{13}$. In Bangladesh, the incidence of eclampsia is alarmingly high, about $16 \%$ of maternal deaths are associated with $\mathrm{it}^{14}$.

The homocysteine-mediated vascular changes are similar to those associated with pre-eclampsia; therefore a hypothesis has been proposed that elevated homocysteine may be associated with this condition ${ }^{15}$. Elevated blood levels of homocysteine are now recognized as an important risk marker for pre-eclampsia and eclampsia ${ }^{1}$. Many studies have demonstrated the relationship between elevated homocysteine and pre-eclampsia or eclampsia ${ }^{10,15-20}$. In Bangladesh, study on homocysteine is very scanty. No reported study so far has been observed on homocysteine in eclampsia. Increased level of homocysteine might be an independent factor associated with eclampsia in Bangladeshi women as well. It could be possible to bring health benefits to people of this country

1. Dr. Monzarin Mahal MBBS, M Phil, Lecturer,Biochemistry, Dhaka Medical College, 2. Dr.Farida Yeasmin MBBS, MD, Lecturer, Biochemistry, Dhaka Medical College, 3.Maj Syed AKM Nurul Amin MBBS, MPH, DADMS, HQ 9 Inf Div (Med. Branch), Savar Cantonment. 4. Dr Afia Shahnaj MBBS, M Phil, Lecturer, Dhaka Medical College. 5. Professor Maliha Rashid, MBBS, FCPS, Head, Obst \& Gynae, Dhaka Medical College, 6. Professor Md. Shahadat Hossain MBBS, M Phil, Head, Biochemistry, Dhaka Medical College. 
by treating hyperhomocysteinemia, if it is proved to be associated with eclampsia. So this case control study was designed in Bangladeshi population to evaluate the serum homocysteine concentration in eclamptic patients that might be helpful for the prognosis and management of eclampsia in Bangladesh.

\section{Materials and Methods}

A case control study was conducted at the Department of Biochemistry, Dhaka Medical College(DMC), Dhaka from July 2006 to June 2007. Total 102 pregnant nonsmokers, free from pre-existing hypertension, cardiovascular disease, cerebrovascular disease, diabetes mellitus, renal disease, liver disease and hypothyroidism were included in the study. Among them 50 were diagnosed cases of eclampsia (Group I) and 52 were matched normotensive healthy pregnant controls (Group II). Subjects were selected from the Department of Obstetrics and Gynaecology, Dhaka Medical College Hospital. Study subjects of both groups were apparently matched with respect to maternal age, gestational age and BMI. Ethical clearance and permission for the study was taken from the concerned Departments and authorities. Informed written consent was taken from patients/ attendants from all the study subjects. With all aseptic precaution morning blood samples of all the study subjects were collected. After centrifuging the blood, serum was separated and stored at $-70^{\circ} \mathrm{C}$. Serum homocysteine concentration was analyzed by fluorescence polarization immunoassay (FPIA) method by Abbot's AxSYM system ${ }^{21}$ and lipid profile was analyzed by enzymatic colorimetric method ${ }^{22}$. The data were analyzed statistically by using SPSS (version 12.00 for Windows). Student's unpaired ' $t$ ' test was performed to see the differences between two groups. The relationship between the variables was explained by the Pearson's correlation test. For all the statistical analyses 2tailed $\mathrm{p}$ values $<0.05$ were considered as significant.

\section{Results}

The study revealed the mean serum homocysteine concentration in cases was $10.44 \pm 4.08 \mu \mathrm{mol} / \mathrm{L}$ and in controls was $7.97 \pm 3.46 \mu \mathrm{mol} / \mathrm{L}$. Among the cases serum homocysteine found significantly increased in comparison to controls $(\mathrm{p}<0.001)$. Serum HDL-

Table I: Distribution of study subjects according to maternal age, gestational age and BMI.

\begin{tabular}{|l|c|c|}
\hline Variables & $\begin{array}{c}\text { Cases }(\mathbf{n}=\mathbf{5 0}) \\
\text { Mean } \pm \text { SD }\end{array}$ & $\begin{array}{c}\text { Controls }(\mathbf{n}=\mathbf{5 2}) \\
\text { Mean } \pm \text { SD }\end{array}$ \\
\hline \multirow{2}{*}{ Age (years) } & $25.30 \pm 5.49$ & $26.75 \pm 4.83$ \\
& $(17-38)$ & $(17-40)$ \\
\hline Gestational age (weeks) & $29.29 \pm 2.86$ & $30.08 \pm 2.80$ \\
$(24-34)$ & $(22-36)$ \\
\hline \multirow{2}{*}{ BMI $\left(\mathrm{kg} / \mathrm{m}^{2}\right)$} & $25.04 \pm 1.01$ & $24.87 \pm 1.49$ \\
& $(22.77-27.41)$ & $(22.19-29.52)$ \\
\hline
\end{tabular}

Values in Parenthesis shows the range cholesterol concentration found significantly decreased $(p<0.001)$ in the cases $(35.98 \pm 6.35 \mathrm{mg} / \mathrm{dl})$ compared to controls $(42.69 \pm 6.09 \mathrm{mg} / \mathrm{dl})$. But no significant differences were found between the cases and controls in respect to serum cholesterol, triacylglycerol and LDLcholesterol. This study also revealed a significant negative correlation $(\mathrm{r}=-.801, \mathrm{p}<0.01)$ between serum homocysteine and HDL-cholesterol among the cases. But no significant correlation was observed between homocysteine and other components of lipid profile.

Table-II: Comparison of Serum Homocysteine level between Case and Control.

\begin{tabular}{|l|c|c|c|l|}
\hline $\begin{array}{l}\text { Parameter } \\
(\boldsymbol{\mu} \text { mol } / \mathbf{L})\end{array}$ & $\begin{array}{c}\text { Cases }(\mathbf{n}=\mathbf{5 0}) \\
\text { Mean } \pm \text { SD }\end{array}$ & $\begin{array}{c}\text { Controls }(\mathbf{n}=\mathbf{5 2}) \\
\text { Mean } \pm \text { SD }\end{array}$ & -value & $\mathbf{p}$-value \\
\hline Homocysteine & $10.44 \pm 4.08$ & $7.97 \pm 3.46$ & 3.179 & $<0.001^{* * *}$ \\
\hline
\end{tabular}

Unpaired-t test was done as the test of significance

*** Highly significant

Table-III: Comparison of Serum Lipid Profile between case and Control.

\begin{tabular}{|l|c|c|l|l|}
\hline $\begin{array}{l}\text { Parameter } \\
\mathbf{m g} / \mathbf{d l}\end{array}$ & $\begin{array}{c}\text { Cases }(\mathbf{n}=\mathbf{5 0}) \\
\text { Mean } \pm \text { SD }\end{array}$ & $\begin{array}{c}\text { Controls }(\mathbf{n}=\mathbf{5 2}) \\
\text { Mean } \pm \text { SD }\end{array}$ & -value & $\mathbf{p}$-value \\
\hline TC $(\mathrm{mg} / \mathrm{dl})$ & $191.22 \pm 33.54$ & $186.50 \pm 23.86$ & .821 & $>0.05$ \\
\hline TG $(\mathrm{mg} / \mathrm{dl})$ & $184.82 \pm 38.49$ & $174.31 \pm 31.21$ & 1.581 & $>0.05$ \\
\hline HDL-C $(\mathrm{mg} / \mathrm{dl})$ & $35.98 \pm 6.35$ & $42.69 \pm 6.09$ & 5.450 & $<0.001 * * *$ \\
\hline LDL-C $(\mathrm{mg} / \mathrm{dl})$ & $130.80 \pm 20.78$ & $125.60 \pm 18.47$ & 1.338 & $>0.05$ \\
\hline
\end{tabular}

Unpaired-t test was done as the test of significance $* * *$ Highly significant

Table-IV: Correlation of Serum homocysteine with the components of Lipid Profile in the cases.

\begin{tabular}{|l|c|l|}
\hline $\begin{array}{l}\text { Independent variable/ } \\
\text { Dependent variable }\end{array}$ & r-value & p-value \\
\hline $\mathrm{Hcy}(\mu \mathrm{mol} / \mathrm{L}) / \mathrm{TC}(\mathrm{mg} / \mathrm{dl})$ & 0.226 & $>0.05$ \\
\hline $\mathrm{Hcy}(\mu \mathrm{mol} / \mathrm{L}) / \mathrm{TG}(\mathrm{mg} / \mathrm{dl})$ & 0.204 & $>0.05$ \\
\hline $\mathrm{Hcy}(\mu \mathrm{mol} / \mathrm{L}) / \mathrm{HLD}-\mathrm{C}(\mathrm{mg} / \mathrm{dl})$ & -0.801 & $<0.01 * *$ \\
\hline $\mathrm{Hcy}(\mu \mathrm{mol} / \mathrm{L}) / \mathrm{LDL}-\mathrm{C}(\mathrm{mg} / \mathrm{dl})$ & 0.151 & $>0.05$ \\
\hline
\end{tabular}

** Correlation is significant at the 0.01 level (2-tailed)

\section{Discussion}

Eclampsia is one of the most leading causes of maternal and perinatal mortality in the developing countries. Approximately $10-15 \%$ of maternal deaths in developing countries are associated with pre-eclampsia and eclampsia $^{2}$. In Bangladesh about $16 \%$ of maternal deaths are associated with it $^{14}$. This figure is quite alarming. So it would be better to diagnose this disease before its clinical manifestations. The prevention of the onset of the disease would have a significant improvement in the maternal and child health. The present study was undertaken to study the changes of some biochemical parameters in eclamptic Bangladeshi women, which may contribute to the proper diagnosis and management of this disease. 
Many studies have demonstrated the relationship between elevated homocysteine and pre-eclampsia; or eclampsia ${ }^{20}$. In this study mean serum homocysteine level was found to be significantly high $(\mathrm{p}<0.001)$ in eclampsia cases as compared to their control value. In consistent with presented findings Rajkovic et $\mathrm{al}^{16}$, Vandergajt et $\mathrm{al}^{12}$ and Cotter et $\mathrm{al}^{6}$ also found homocysteine concentration to be raised in eclampsia patients. Makedos et al. ${ }^{19}$, Wang et al. ${ }^{8}$, Aubard et al. ${ }^{23}$, Powers et $\mathrm{al}^{18}$ demonstrated the relationship between hyperhomocysteinemia and preeclampsia without showing any attention to the severity of pre-eclampsia; and degree of hyperhomocysteinemia. Present study also revealed significantly low $(\mathrm{p}<0.001)$ serum HDL-C concentration in cases compared to controls, which is similar to the studies conducted by Ware-Jauregui et $\mathrm{al}^{5}$, Belo et $\mathrm{al}^{11}$ Vandergajt et $\mathrm{al}^{12}$, Bayhan et $\mathrm{al}^{24}$ Baksu et $\mathrm{al}^{25}$. Regarding TG concentrations, no significant changes were observed in the cases compared to controls. This is consistent with De, Mukhopadhay and $\mathrm{Saha}^{26}$, Vandergajt et $\mathrm{al}^{12}$ and Mikhhail et al. ${ }^{27}$. Similarly for TC and LDL-C, eclampsia cases did not reveal any significant changes in comparison to controls. These results are supported by the findings of the study undertaken by De, Mukhopadhay and $\mathrm{Saha}^{26}$, Vandergajt et $\mathrm{al}^{12}$ and Baksu et $\mathrm{al}^{25}$. Reported study also revealed a significant negative correlation between serum homocysteine and HDL-C in eclampsia cases. No significant correlation was found between homocysteine and other components of lipid profile (TC, TG, LDL-C), which is consistent with the findings of Vandergajt et $\mathrm{al}^{12}$ and Powers et $\mathrm{al}^{18}$.

This study observed significantly increased serum homocysteine level and decreased HDL-C without any significant changes in TC, TG and LDL-C in eclampsia cases compared to control. Moreover serum homocysteine demonstrated no significant correlation with lipid profile except the negative correlation with serum HDL-C in eclampsia cases. Thus, serum homocysteine appears to be an independent factor associated with eclampsia irrespective of lipid profile status.

\section{Conclusion}

It can be concluded from this study that increased homocysteine level and isolated HDL-C deficiency are associated with eclampsia. Decreased HDL-C and increased homocysteine level may have additive or synergistic effect on pathophysiology of eclampsia. Early detection is the corner stone for proper management of eclampsia, which will reduce the maternal mortality rate and infant mortality rate. For early detection a reliable, simple and inexpensive laboratory test is essential. Serum homocysteine measurement can be used for this purpose. So serial estimation of serum homocysteine could be advised from the 1st trimester of pregnancy for early detection of pre-eclampsia and eclampsia. Folate, vitamin $B_{12}$ and vitamin $B_{6}$ are involved in the metabolism of homocysteine $^{28}$. Elevated homocysteine is a marker of low vitamin B status or decreased methylation capacity of cells $^{29,30}$. So vitamin $\mathrm{B}_{6}, \mathrm{~B}_{12}$ and folic acid supplementation could have a role in preventing the elevation of homocysteine in pregnant women ${ }^{29}$. Pregnant ladies having increased homocysteine may bring under special management with the target to normalize their serum homocysteine with vitamin $\mathrm{B}_{6}, \mathrm{~B}_{12}$ and folic acid supplementation to prevent eclampsia. But the use of serum homocysteine measurement as a screening test for eclampsia warrants further investigation.

\section{References}

1. Niyazi T, Hasnu C, Gurkan C, Oguz O, Ahmet A. The correlation between plasma homocysteine and malondialdehyde level in preeclampsia. Journal of Neuroendocrinology 2003; 24 (6): 446-48.

2. Dulay L. Maternal mortality associated with hypertensive disorders of pregnancy in Africa, Asia, Latin America and the Caribbean. British Journal of Obstetrics and Gynaecology 1992; 99(7): 547-53.

3. Mabie WC, Sibai BM. Hypertensive states of pregnancy. In: DeCherney AH, Pernoll ML, editors. Current obstetric \& gynecologic diagnosis \& treatment. USA: Appleton and Lange; 1994.p. 380.

4. Dutta DC. Text book of obstetrics including perinotology \& contraception. 3rd ed. Calcutta: New Central Book Agency; 1997.

5. Ware-Jauregui S, Sanchez SE, Zhang C, Laraburre G, King IB, Williams MA. Plasma lipid concentrations in pre-eclamptic and normotensive Peruvian women. Int J Gynaecol Obstet 1999; 67(3): 147-55.

6. Cotter AM, Molloy AM, Scott JM, Daly SF. Elevated plasma homocysteine in early pregnancy: a risk factor for the development of severe preeclampsia. American Journal of Obstetrics and Gynaecology 2001; 185(4): 781-85.

7. Refsum H, Uelend PM, Nygard O, Brattstrom L, Vollset SE. Total homocysteine and cardiovascular disease. Journal Internal Medicine 1999; 246: 425-54.

8. Wang J, Brian J, Trudinger BJ, Duarte N, Wilcken DE, Wang XL. Elevated circulating homocysteine levels in placental vascular disease and associated pre-eclampsia. British Journal of Obstetrics and Gynaecology 2000; 107(7): 935-38.

9. Welch GN, Loscalzo J. Homocyeseine and atherothombosis. The New England Journal of Medicine 1998; 338(15): 1042-50.

10. Walker MC, Smith GN, Perkins SL, Kelly EJ, Garner PR. Changer in homocysteine levels during normal pregnancy. American Journal of Obst. and Gynaecology 1999; 180(3): 660-64.

11. Belo L, Caslake M, Gaffney D, Santos-Silva A, Pereira-Leite L, Quintanilha A, Rebelo I. Changes in LDL size and HDL concentration in normal and preeclamptic pregnancies. Atherosclerosis 2002; 162(2): 425-32.

12. Vanderjagt DJ, Patel RJ, El-Nafty AU, Melah GS, Crossey MJ, Glew RH. High density lipoprotein and homocysteine levels correlate inversely in preeclamptic women in northern Nigeria. Acta Obstetricia et Gynecologica Scandinavica 2004; 83(6): 536-42.

13. Bangladesh Bureau of Statistics. Ministry of Planning. 2004, National census 2002.

14. Rashid KM, Rahman M, Hayder S. Text book of community medicine and public health. 4th edition. Dhaka: RHM publishers; 2004.

15. Rajkovic A, Catalano PM, Malinow MR. Elevated homocysteine levels with preeclampsia. Obstetrics \& Gynecology 1997; 90: 168-71.

16. Rajkovic A, Mahomed K, Malinow MR, Sorensen TK, Woelk GB, Williams MA. Plasma homocysteine concentrations in eclamptic and preeclamptic African women postpartum. Obstetrics \& Gynecology 1999; 94: 355-60.

17. Ingec M, Borekci B, Kadanali S. Elevated plasma homocysteine concentration in severe PE and eclampsia. Tohoku Journal of Experimental Medicine 2005; 206(3): 225-31.

18. Powers RW, Evans RW, Majors AK, Ojimba JI, Ness RB, Crombleholme WR, Roberts JM. Plasma homocysteine concentration is increased in preeclampsia and is associated with evidence of endothelial activation. American Journal of Obst Gynae 1998; 179(6): 1605-11.

19. Makedos Georgios, Papanicolaou Alexis, Hitoglou Areti, Kalogiannidis Ioannis, Anastasios Vrazioti, violeta Goutzioulis, Michalis. Homocysteine, folic acid and B12 serum levels in pregnancy 
complicated with pre-eclampsia. Archives of Gynecology and Obstetrics 2007; 275(2): 121-24.

20. Cotter AM, Molloy AM, Scott JM, Daly SF. Elevated plasma homocysteine in early pregnancy: a risk factor for the development of nonsevere preeclampsia. American Journal of Perinotology 2003; 189(2): 391-94.

21. Refsum H, Smith AD, Ueland PM,et al .Facts and recommendations about total homocysteine determinations: An expert opinion. Clinical Chemistry2004; 50: 3-32.

22. Allain CA, Poon LS, Chan CS, Richmond W, Fu PC. Enzymatic determination of serum total cholesterol. Clinical Chemistry 1974; 20: 470 . 23. Aubard Y, Darodes N, Cantaloube M, Aubard V, Diallo D, Teissier MP. Hyperhomocysteinemia and pregnancy: a dangerous association. Gynecol Obstet Biol Reprod 2000; 29(4): 363-72.

24. Bayhan G, Kocyiqit Y, Atamer A, Atamer Y, Akkus Z. Potential atherogenic roles of lipids, lipoprotein (a) and lipid peroxidation in preeclampsia. Gynecol Endocrine 2005; 21(1): 1-6.

25. Baksu B, Baksu A, Davas I, Akyol A, Gulbaba G. Lipoprotein (a) levels in women with pre-eclampsia and in normotensive pregnant women. J Obstet Gynecol Res 2005; 31(3): 277-82.

26. De J, Mukhopadhay AK, Saha PK. Study of serum lipid prifile in pregnancy induced hypertension. Indian Journal of Clinical Biochemistry 2006; 21(2): 165-68.

27. Mikhail MS, Basu J, Palan PR, Furqiuele J, Romney SL, Anyaeqbunam A. Lipid profile in women with preeclampsia: relationship between plasma triglyceride levels and severity of preeclampsia. J Assoc Acad Minor Phy 1995; 6(1): 43-5.

28. Strain JJ, Dowey L, Ward M, Pentieva K, McNulty H. B-vitamins, homocysteine metabolism and CVD. Nutrition Society 2004; 63: 597-603. 29. Castro R, Rivera I, Struys EA, et al. Increased homocysteine and Sadenosylhomocysteine concentrations and DNA hypomethylation in vascular disease. Clin Chem 2003; 49: 1292-96.

30. Patric TE, Powers RW, Daftary AR, Ness RB, Roberts JM. Homocysteine and folic acid are inversely related in black women in pre-eclampsia. Hypertension 2004; 43: 1279. 